\title{
A vida no banco de dados: a visibilidade do corpo informacional e a previsão de individualidades
}

\author{
César Pessoa Pimentel", Fernanda Clória Bruno"
}

\begin{abstract}
Resumo
A noção de informação juntamente com seu tratamento e armazenamento em banco de dados definem pontos de convergência entre as técnicas de controle da conduta e as intervenções biotecnológicas sobre o corpo. Ambas atuam sobre elementos impessoais recombináveis segundo técnicas digitais, ao invés de indivíduos e corpos definidos por uma interioridade que não pode ser totalmente observada. Trata-se, pelo contrário, de prever o que ainda não existe na atualidade, de ir além dos hábitos e condutas do individuo no presente para inferi-los em cenários futuros. O presente artigo aborda essas convergências, analisando o papel da gestão da informação e da administração de riscos na produção de identidades somáticas, tendo como pano de fundo a questão da visibilidade dos individuos e dos corpos.
\end{abstract}

Palavras-chaves: informação, banco de dados, biotecnologias, individuo

\begin{abstract}
The concept of information along with the way it is dealt and stored in databases define converging points between the techniques of conduct control and the biotechnological interventions on the body. Both act over matching impersonal elements according to digital techniques, instead of individuals and bodies defined by an interiority that resists against externalization. Actually, it is to forecast what still does not exist nowaday's, to go beyond habits and conducts of the individual in the present 10 infer on them in future scenarios. This article treats these converging points, analyzing the role of the information management and the risk management in the production of somatic identities, having as background the issue of the visibility of the individuals and bodies.
\end{abstract}

Keywords: information, data bunks, biotechnology', individual.

\footnotetext{
- Psicólogo graduado na UFRJ, mestre em Psicossociologia e Ecologia Social pelo Programa EICOS da UFRJ, doutorando do mesmo programa

Doutora em Comunicação pela UFRJ, Professora do Programa de Pós-Graduação em Comunicaçào e Cultura da UFRJ, Professora Colaboradora do Programa EICOS/UFRJ e Coordenadora do CiberIDEA Núcleo de pesquisa em tecnologia, cultura e subjetividade - ECO/UFRJ.
} 
'Obrigado por virar esta página. Agora nós temos uma amostra do seu DNA'

(Gattaca, de Andrew

Niccol)

A vida no banco de dados. A frase-título é quase caricatural, mas ressalta uma tendência bem real da lógica informacional contemporânea: ela passa não apenas a reger a nossa 'cultura', mas também a nossa 'natureza', trazendo consequiências significativas para a gestão da vida, em particular para as práticas de cuidado e controle dos corpos e dos indivíduos. As biotecnologias, ao conceberem o corpo como um sistema informacional, se inserem na problemática contemporânea da produção de individualidades e identidades. As atuais técnicas de visibilidade do código genético, identificado a um conjunto de informaçôes que pode ser armazenado, analisado e tratado em bancos de dados, procuram revelar identidades somáticas, atrelando-se a uma série de dispositivos de controle que agem através da previsão e predição da conduta e de riscos de adoecimentos futuros. O cruzamento de bancos de dados que conectám informações genéticas a fatores geográficos, epidemiológicos, econômicos, médicos, familiares etc produz perfis de indivíduos, que concernem menos a diagnósticos de sua condição presente ou atual do que a simulações ou projeções de sua condição futura ou virtual. O papel central que a noção de fator de risco ocupa na composição destes 142 perfis irá atrelar a individualidade ao campo exterior do comportamento e dos hábitos de vida, assinalando uma crise na individualidade moderna e a sua tópica da interioridade.

O presente artigo pretende examinar o plano comum sobre o qual se assentam a produção do corpo informacional e os procedimentos de previsão e simulação de identidades a partir da análise e processamento de informações em bancos de dados. Informação e banco de dados correspondem, de forma aproximada, ao elemento e ao aparato que assinalam a convergência entre esses dois processos. Tendo como pano de fundo a questão da visibilidade do corpo e do indivíduo, apresentaremos nossa temática em três etapas. Inicialmente, abordaremos a constituição do indivíduo na modernidade, através de práticas disciplinares, terapêuticạs e hermenêuticas, que lhe asseguram uma interioridade relativamente opaca. Trata-se de mostrar também que a identidade moderna é produzida concomitantemente ao trabalho de técnicas políticas sobre a superfície do corpo, que o expõem à visibilidade, mas reservando-lhe uma profundidade imperscrutável. Em uma segunda parte, passamos à análise do corpo informacional, das concepções científicas que o sustentam e dos procedimentos que o modelam. Procura-se assinalar o caráter exposto e visível do texto que constitui estes corpos, bem como a lógica de antecipação e simulação de perfis de indivíduos a partir do registro, análise e utilização de informações biológicas em bancos de dados. Por último, 
relacionamos estes últimos pontos com a lógica do risco, procurando apreender as suas implicações para as práticas de cuidado e controle dos indivíduos. Pretende-se mostrar como a simulação de identidades somáticas e a previsão de riscos promove nexos estreitos entre a informação, o poder e o dever, engajando de um modo constrangedor a responsabilidade dos indivíduos diante de sua doença e sua saúde, sua vida e sua morte.

\section{1) As superfícies do bio-poder moderno e a construção da interioridade.}

A fim de compreendermos o papel da informação nas práticas contemporâneas de cuidado e controle dos corpos e dos indivíduos, vale recuarmos nosso olhar para a Modernidade. Pretende-se mostrar como os dispositivos próprios à sociedade moderna e disciplinar efetuam uma série investimentos técnicos e políticos no corpo e na vida, participando da constituição de indivíduos que portam uma subjetividade interiorizada. Veremos como este investimento disciplinar no corpo articula-se a uma determinada concepção de sua natureza e das relações que aí vigoram entre $o$ interior e o exterior, o profundo e o superficial. Apontaremos ainda, tanto na topologia da subjetividade moderna quanto na dos corpos modernos, a presença de jogos de sombra e luz, de opacidades e transparências, de visibilidade e invisibilidade.

Sabe-se que um dos campos de investimento do poder disciplinar é a superfície dos corpos - a face visível dos gestos, da atividade, dos movimentos, dos exercícios, do cumprimento das regras, regulamentos, horários. A este campo se associa uma escala ótica e uma estratégia de visibilidade que pretende ser ao mesmo tempo minúscula e total. Minúscula porque a disciplina, tal como Foucault (1983) a descreve, é uma anatomia política do detalhe que estende ao mundo laico e ao indivíduo comum o que já importava para a teologia e o ascetismo:

a mística do cotidiano aí se associa à disciplina do minúsculo ... A minúcia dos regulamentos, o olhar esmiuçante das inspeções, o controle das mínimas parcelas da vida e do corpo darão em breve, no quadro da escola, do quartel, do hospital ou da oficina, um conteúdo laicizado, uma racionalidade econômica ou técnica a esse cálculo místico do ínfimo e do infinito (Idem: 129).

A observação minuciosa do detalhe torna notável, no sentido de significativo e visível, uma série de pequenas coisas que costumava ser ignorada pelos grandes sistemas morais e jurídicos, devido a sua relativa indiferença: atrasos, ausências, interrupção de tarefas, negligências, grosserias, imodéstias, indecências (Idem: 159). Mas a observação e o controle dos corpos também 
deve ser total. A vigilância panóptica, como se sabe, deve constituir um olho perfeito, maximamente eficaz na capacidade de tudo ver e maximamente econômico no seu exercício, pois deve ser discreto, anônimo e automático de modo a produzir uma vigilância que seja ininterrupta e total nos seus efeitos, ainda que descontínua na sua ação (Idem: 177-8).

Todo esse investimento na superfície dos corpos, gestos e atividades, todo este jogo de olhares e vigilâncias ininterruptas deve escavar uma profundidade, uma interioridade, um desdobramento incorpóreo - alma, psiquismo, subjetividade. As táticas disciplinares de visibilidade e vigilância só se tornam efetivas ao constituírem uma auto-vigilância. $\mathrm{O}$ olhar do outro deve ser interiorizado e constituir um olhar sobre si, deve abrir todo um outro campo de visibilidade que se situa agora no interior do próprio indivíduo (pensamentos, desejos, paixões) e que deve ser 'observado', nos vários sentidos da palavra, por ele mesmo. É nesta medida que a tecnologia disciplinar é uma tecnologia do corpo que visa, e mesmo produz, a alma moderna. É também neste sentido que esta alma pode aprisionar o corpo, pois a docilidade deste último não é apenas um efeito de coerções externas mas sobretudo de cuidados que se exercem de si para consigo.

O que se deseja ressaltar é que a inscrição do poder disciplinar na superfície dos corpos corresponde a uma subjetividade interiorizada, dobrada . sobre si mesma que, no recolhimento de uma profundidade, pode prolongar o olhar normalizador ou the resistir. De todo modo, este "espaço" profundo e 144 interior é concebido como uma realidade mais autêntica e verdadeira, que pode se distinguir ou mesmo se opor à exterioridade, ainda que se constitua numa íntima relação com esta.

A esta topologia associa-se todo um jogo de sombra e luz, de opacidades e transparências. Á natureza recôndita da verdade do indivíduo moderno guarda muitas vezes um parentesco com a sua natureza opaca, invisível não apenas ao olhar do outro mas também ao próprio sujeito. A problemática do inconsciente e os diversos saberes e terapêuticas "psi" participam ativamente da constituição desta verdade tão mais "autêntica" quanto menos visível e dizível. A posição privilegiada que a sexualidade ocupa nas concepções médicas e psicológicas de doença mental ilustra bem esta identificação da verdade com a porção inconsciente e involuntária, simultaneamente mais secreta e determinante do sujeito. Não por acaso, instaura-se toda uma hermenêuticá de si que persegue

esse segredo que nos parece subjacente a tudo que somos ..., ao qual pedimos revelar o que somos e liberar-nos o que nos define (Foucault, 1984: 145).

O estatuto da sexualidade moderna nos permite, ainda, retomar as relações entre o corpo e as identidades modernas, agora no âmbito das táticas 
do bio-poder'. Ao continuar de modo renovado o poder pastoral, matriz de um poder que concerne à vida e à salvação dos indivíduos. o bio-poder ao mesmo tempo mantém e recria, no domínio da Razão de Estado. uma economia individualizante onde prevalecem os temas da vida, da saúde. da verdade interior e da sexualidade. Com a consolidação do bio-poder no século XIX. a intervenção do poder político na vida dos indivíduos encontra-se aumentada. O poder do Estado se constitui como uma complexa combinação de técnicas de individualização e procedimentos totalizadores. É preciso combinar uma gestão da população, noção que ganha força ao longo do século XVIII. com um cuidado com os indivíduos que a constituem (Fouciult, 1994a: 159). As ciências humanas e sociais encontram aí um solo fértil de desenvolvimento na medida em que 'levam em conta problemas de comportamento individual no interior da população e as relações entre uma população viva e seu meio: (Foucault. 1994b: 827). O saber sobre o homem se dirige a dois campos fundamentais: um, globalizante e quantitativo. concernente à população. e outro, analítico, concemente ao indivíduo (Foucault. 1994a: 231). De um lado, programas estatais de regulação das populações - proliferação. nascimentos e mortalidade, nível de saúde, tabulação das riquezas e de sua circulação. condições de vida, longevidade. etc.. De outro lado. a masssa das instituições que se centram sobre os indivíduos e seus comportamentos: conhecer. interrogar, hierarquizar, adestrar, curar.

A sexualidade ocupa um lugar privilegiado neste processo na medida em que articula os dois pólos investidos pelo bio-poder e pelo saber sobre o homem que the é correlato. O sexo articula o somático e o psíquico, bem como o coletivo (pela regulação das populações) e o individual (pelo controle. principalmente médico e pedagógico, do corpo sexualizado dos indivíduos). Nola-se que o bio-poder inscreve-se não apenas na superfície dos corpos. como se mostrou nas tecnologias disciplinares. como também ingressa $\mathrm{cm}$ seu interior, seja pela via da regulação de uma sexualidade supostamente escondida nas profundezas do corpo e nas suas fronteiras com o psíquico. seja pela via do que se concebe ser a naturcza do corpo dócil. cujas técnicas disciplinares que se the aplicam do exterior devem "respeitar" seus ritmos e limites internos. Dado que o corpo dócil deve também ser útil e produtivo, as técnicas de adestramento não podem ultrapassar limites que a natureza impõe. sob pena de comprometer os efeitos de utilidade desejados (Foucault. 1983: 140-141).

Reencontramos no domínio do corpo o que já se viu no âmbito da identidade. Ainda que o bio-poder suponha um corpo que se oferece ao adestramento, à vigilấncia e à decifração, este corpo se oferece a uma visibilidade que é apenas parcial. A interioridade do corpo, suas camadas mais profundas e mais íntimas guardam uma opacidade que resiste ao olhare mesmo à intervenção. O corpo moderno participa de um regime de visibilidade 
e controle onde ainda há reserva e espaço para o imperscrutável, o secreto e o que escapa ao conhecimento e à ação humana. É nesta medida que a natureza pode ser o reino da necessidade e a biologia pode ser um destino para os homens modernos.

Diferentemente, o regime de visibilidade que se aplica sobre os corpos contemporâneos parece incidir sobre as suas menores e mais íntimas porções e não deixar nenhuma região de sombra. $O$ Visible Human Project ${ }^{2}$ e o Projeto Genoma Humano ilustram a radicalidade e a extensão dessa visibilidade. $O$ corpo aí é visível não apenas como sistema de órgãos, mas como sistema de informação, o que o torna amplamente manipulável e modulável. As biotecnologias e práticas biomédicas contemporâneas participam de uma nova relação entre o corpo e a tecnologia, entre a natureza e o artifício. Afirma-se que tais domínios partilham desde então uma mesma "constituição" informacional. E o corpo parece tender a não guardar mais nenhum segredo, exterioridade ou fatalidade frente à intervenção técnica. Estes novos dispositivos de visibilidade e manipulação dos corpos dissolvem o seu peso e a sua massa transformando-os em porções de informação que podem ser desmontadas e remontadas em bancos de dados (Garcia Dos Santos, 2004). E este corpo de uma natureza sem reservas, de uma matéria sem resistências parece não mais corresponder a uma subjetividade interiorizada e recôndita. Ao corpo informacional corresponde um indivíduo cuja face encontra-se cada vez mais visível ou mesmo "pre-visível" nos bancos de dados.

\section{2) O corpo informacional e os bancos de dados.}

A utilização de dispositivos tecnológicos que permitem desvelar a profundidade do corpo pode ser remontada ao século XIX. Desde então, aparatos, como os raios $X$, projetam no espaço externo acontecimentos inscritos no interior do organismo, considerados de difícil acesso e comunicação (Vieira, 2003). A dor e a doença, antes fundamentalmente extraídas mediante o olhar clínico e a partir do discurso do paciente, passam a se apresentar segundo novas espacialidades e visibilidades. O corpo tem seu espaço desdobrado na textura e ritmo conferidos pela tecnologia, aparecendo em uma exterioridade própria que, longe de um mero reflexo desse interior, é, fundamentalmente, abertura a intervenções que mudam o seu estatuto, a sua experiência e até a sua "natureza".

As intervenções biotecnológicas não apenas prolongam e aprofundam esse movimento, mas introduzem novas descontinuidades: além de iluminarem o corpo como um texto totalmente aberto à observação, possibilitam decompôlo (e até mesmo recompô-lo) em seus elementos moleculares, cuja natureza e funcionamento são compreendidos como informação. À luz dos mecanismos biopolíticos contemporâneos, o que está em jogo nesta concepção do corpo é menos o indivíduo do que o infra-individual, menos a sincronicidade 
entre o exame e a doença do que a antecipação do surgimento de sintomas. menos a densidade subjetiva e histórica do que uma identidade definida segundo circunstancias objetivas e quantificáveis. Instaurado sobre os múltiplos feixes de um bio-poder renovado, a compreensão informacional do corpo funciona suspendendo a consistência orgânica e introduzindo um regime de controle e modificação da conduta que minimiza o papel de qualquer instância interior.

Em sua origem, a concepção de um corpo informacional pode ser associada às tentativas efetuadas pela Cibernética, ciência fundada por Norbert Wiener, no sentido de compreender scres vivos e objetos técnicos auto-regulados segundo uma mesma identidade funcional (Dupuy, 1996). Ainda que a concepção cibernética de organismo e a sua extensão aos sistemas não humanos tenha sido questionada (Varela, 1993), ainda que a relação entre informação e matéria seja objeto de muita divergência (Hayles. 1998), a cibernética contribui para a constituição de uma das principais características culturais de nosso tempo: a suposição de que a realidade e os entes materiais, do DNA a Internet, são interpenetrados por fluxos informacionais, e de que a informação pode circular inalterada entre diferentes substratos materiais. Consagradas pela biologia molecular. as comparações entre código genético e linguagem tornaram-se bastante populares:

assim como uma frase constitui um segmento de lexto, um gen corresponde a um segmento de ácido nucléico. Nos dois casos, um símbolo isolado não representa nada; só a combinação dos signos adquire "um sentido" (Jacob. 1983: 277).

A terminologia que funda a própria biologia molecular, abrindo-the para a compreensão do código genético, foi importada da descrição das atividades comunicativas entre seres humanos. na qual a idéia de informaçĩo é decisiva ${ }^{3}$. A informação no caso da biologia molecular corresponde à ordem dos radicais nucléicos - uma espécie de texto - que. através de um complexo trabalho de tradução, sintetiza proteínas.

À diferença dos corpos na modernidade. tal texto não faz qualquer demanda por técnicas hermenêuticas. Como um impensado que, no entanto. instituía o pensamento, parte da dimensão orgânica precisava ser recoberta pelo movimento da consciência, tornando possivel o conhecimento do homem sobre si mesmo. Nessa distância entre o pensamento e aquilo que o constitui. aparece o que é próprio da subjetividade moderna: uma interioridade, que. por princípio, se furta à observação. Pode-se dizer que havia texto nesse corpo - como nos casos diagnosticados pela psicanálise de histeria conversiva-, mas sempre compreendido como un efeito de sentido, 
possibilitado pela disparidade fundamental entre a consciência e o impensado ${ }^{4}$. Uma das diferenças entre o corpo moderno e o corpo biotecnológico é a natureza desse texto e de sua produção de sentido. $O$ sentido produzido no corpo informacional está relacionado a mecanismos bioquímicos, que não pressupõem intencionalidade e, por conseguinte, qualquer estrato profundo do psiquismo. Para modificá-lo não se faz mais necessário o trabalho mediador da representação, já que a intervenção sobre o código genético pode ser feita diretamente através de tecnologias como a engenharia genética ou a terapia gênica. Trata-se, portanto, de um texto destituído de sentido oculto, integralmente visível e desdobrável na exterioridade. Neste sentido, o corpo biotecnológico é um corpo que se abre e se torna informação, quantificação e distribuição de dados.

Dois fenômenos contemporâneos ilustram com a devida clareza essa conversão: o Projeto Genoma Humano e o patenteamento de células germinativas humanas. No primeiro caso, o que está em jogo é o conhecimento da microestrutura da espécie humana tendo em vista estocar essas informações para uso médico, através, por exemplo, da detecção de fatores genéticos envolvidos em certos tipos de doenças. No entanto, essa estocagem de informações já pressupõe o próprio corpo como um objeto técnico, uma espécie de arquivo onde as informações se dispõem ao uso. Como ressalta Waldby (Garcia dos Santos, op. cit.), tais práticas não estão se valendo simplesmente de metáforas computacionais: elas efetivamente modelam o corpo dessa forma, 148 inscrevendo sua estrutura sobre o campo informacional, onde os dados correspondem à natureza genética. Modificação introduzida na ordem da vida, que a integra ao domínio do artifício.

Os limites do humano como espécie são estabelecidos como uma ampla embora finita base de dados informacionais, uma ordenação espacial e gráfica que atua como um arquivo digital, recuperável através de redes computadorizadas e legível em estações de trabalho (Waldby apud idem: 268).

Esse diagnóstico talvez se torne ainda mais grave no caso do patenteamento de células humanas, caso ocorrido, pela primeira vez, nos Estados Unidos, quando um médico da U.C.L.A. registrou a patente de células extraídas do baço de um paciente. Ao saber desse uso comercial de partes de seu corpo, o paciente reclamou, em ação jurídica, participação nos lucros, alegando apropriação indébita de suas células. Em 1990, a ação é julgada no Supremo Tribunal da Califó́rnia, que decide que o paciente não tem direitos de propriedade pessoal sobre as células retiradas de seu corpo. A decisão é 
fundamentada sobre dois pontos principais: a alegação de que as células não podem ser consideradas propriedade pessoal e o fato de a utilização das células ter sido destinada a pesquisas para melhoria da saúde pública (Rabinow, 2002). Isso significa que as células de um corpo humano puderam ser legalmente conectadas a um aparato tecno-científico-econômico e seus elementos geneticamente disponibilizados à transformação para a produção de medicamentos. Ao invés de totalidade orgânica, o corpo foi tratado como um conjunto de informaçôes potencialmente modificáveis. Conseqüentemente, seu valor como entidade atual e individualizada é depreciado, em prol da plasticidade, da possibilidade de haver reconstrução de seu ser sob estado de mercadoria.

Se a medicina moderna deteve-se na profundidade dos corpos individualizados, as intervenções genéticas atravessam a barreira do atual, incidindo sobre os fluxos e processos que constituem o indivíduo e seu porvir. E se as biotecnologias ingressam nas menores e mais íntimas peças de nossa constituição biológica, é para tornar esta profundidade transparente e superficial, acessível à ação e à manipulação Num mesmo movimento, a transparência do gene confere uma profundidade à superfície do corpo. Na pele e nos os pêlos residem não apenas os traços superficiais e visíveis. mas os traços profundos e inequívocos da identidade genética, agora identificável por diversos tipos de controle. Embora 'naturalmente' a pele seja um espaço de revelação, exibição ou exposição, ela sempre pôde guardar, proteger ou manter em segredo. No que concerne à identidade genética, parece não haver reserva possivel - toda informação encontra-se na pele, disponível ao escrutínio alheio. Basta lembrarmos do filme Gattaca, de Andrew Niccol. que retrata uma sociedade onde se privilegiam os indivíduos geneticamente produzidos: o personagem 'nascido 'naturalmente' retira sua última camada de pele, caspa e pêlos - tudo o que na superfície carrega seus dados pessoais mais profundos e o expõe à identificação pelo controle' (Senra, 2000). 'A única coisa que conta é a informação', diagnostica Garcia dos Santos (op. cit: 84). E essa valorização implica conceber e tratar o corpo como um arquivo digital, cujas porções, além de totalmente visíveis. dispõem-se à transformação.

Se o corpo é um texto informacional, a sua morada é o Banco de Dados. Este corpo informacional, ao mesmo tempo de todos e de ninguém, reside doravante em bancos que armazenam dados biológicos, genéticos, epidemiológicos, médicos, demográficos etc. Estes dados não concernem. primeiramente, a indivíduos ou pessoas particulares, mas a grupos, populações, categorias, contextos. Eles se situam inicialmente num nível infraindividual. No entanto, eles não têm apenas a função de arquivo ou registro. mas principalmente uma função conjugada de predição, prevenção e intervenção. Com o auxílio de programas computacionais de processamento 
de informação e composição de perfis, os bancos de dados pretendem conter tanto o saber quanto o controle sobre o presente e o futuro dos corpos. A lógica do banco de dados é menos a da precisão ou exatidão no règistro da informação do que a da agilidade e eficiência na recuperação e na utilização da informação (Cf́. Poster, 1995). O processamento e o cruzámento de dados inicialmente impessoais e organizados em categorias amplas irão projetar, simular e antecipar perfịs que correspondem a indivíduos e corpos "reais" a serem pessoalmente monitorados, cuidados, tratados, informados etc. $\mathrm{O}$ banco de dados e as técnicas computacionais que lhe correspondem promovem a passagem do infra-individual para o individual, constituindo um saber não apenas sobre a identidade somática atual dos indivíduos, mas também sobre os ríscos a que eles estão sujeitos, as doenças que podem vir a desenvolver, bem como as ações que podem (ou devem) fazer para conjurálos. Um saber, póis, que rastreia o passado, o presente e o futuro, e cuja verdade independe de qualquer vínculo com a experiência ou a interioridade de cada um. Um saber que é ao mesmo tempo controle, pois antecipa o que cada um é, o que deve fazer e o que pode esperar (Novas \& Rose, 2000). O ritual moderno do exame e seus procedimentos hermenêuticos são substituídos pelos perfis computacionais e seus procedimentos algorítmicos e estatísticos ${ }^{5}$.

\section{3) Previsão, risco e individualidade somática.}

The social meaning of information in the 1990s must be reconsidered in the context of an increasing sense of crisis - over criminal violence, the cost of health care services, the quality of education and the general state of the economy ... These economic and social imperatives are enhancing the social value of predictive testing and reinforcing the power of biological information well beyond the clinical context (Nelkin \& Tancredi, 1994: ix-x).

Com o surgimento de tecnologias que fazem do corpo um sistema informacional, nota-se alterações nas técnicas de controle dos indivíduos. A sociedade disciplinar ápresenta sinais de uma crise, notadamente, em suas instituições, impelindo o poder para além dos limites do confinamento, fazendo com que invista sobre os corpos em suas passagens e suposta liberdade (Deleuze, 1992). A valorização dos fluxos e processos corporais, juntamente ao con̈trole sobre os sujeitos libertos do confinamento institucional sugerem uma nova dinâmica para os investimentos do poder. A esta nova dinâmica do poder corresponde um novo regime de visibilidade, com fortes implicações na constituição de indivíduos e identidades. $O$ corpo informacional moldado pelas biotecnologias e residente nos bancos de dados é liberado da densidade orgânica e ingressa em um regime de altíssima visibilidade, onde ver implica "pre-ver". 
Do ponto de vista das técnicas de controle, tal ruptura pode ser atribuída à predominância de técnicas de prevenção sobre as de vigilância. Ou melhor, esta face da vigilância contemporânea é essencialmente preditiva e preventiva. Embora a vigilância disciplinar abarcasse medidas profiláticas, não estava inteiramente orientada para a antecipação dos desvios possíveis. Além disso, nos casos que estamos visando. o ato de vigilância não se dá sobre corpos e sujeitos individualizados e constituídos. O poder passou a atuar na dimensão infra-individual, em um estado perpetuanente instável do ser, para daí projetar e antecipar indivíduos e identidades potenciais. Castel nos ajuda na comparação em jogo:

segundo o modelo panóptico, a vigilância supõe uma co-presença dos controladores e dos controlados num espaço homogêneo que o olhar varre... As novas políticas preventivas economizam essa relação de 'imediaticidade', porque aquilo de que elas tratam, num primeiro tempo ao menos, não são indivíduos, mas fatores, correlações estatísticas (op. Cit: 145-6).

Na Modernidade, o indivíduo está presente desde o início do processo de vigilância e ainda que esta venha constituir ou transformar sua identidade, a presença física do louco, do criminoso, do perverso, do doente é desde o início requerida. E o que faz deles esses seres marginais e anormais é o peso de uma história familiar, a força insistente de impulsos inconscientes, uma intrincada e obscura causalidade psicológica, uma trama complexa de desejos. inclinações que vêm determinar, do interior em sombra. uma série de ações. comportamentos e hábitos exteriores e visíveis. Eis porque, como se mostrou. a vigilância moderna deve ver e agir através, sob a superfície dos corpos e comportamentos de modo a incidir sobre a interioridade, a alma dos indivíduos. $\mathrm{Na}$ atualidade, trata-se sobretudo de ver adiante, de prever e predizer. a partir dos cruzamentos e análises de dados, indivíduos e seus atos potenciais. seja para contê-los (como no caso de crimes, doenças ou comportamentos indesejados) seja para incitá-los (como no caso da adoção de ações e medidas que contribuam para aumentar a segurança ou diminuir o risco de contrair doenças etc). 'Assim se esboça a possibilidade de uma gestão previsional de perfis humanos' (Castel, op. cit: 130).

O controle e predição de indivíduos e identidades a partir do cruzamento de bancos de informação biológica com bancos de dados de outros tipos (demográfico, financeiro, hábitos de consumo, criminal, profissional. estilo de vida etc) está intimamente relacionado à mobilização da categoria de risco, substituindo a oposição normal-patológico (Vaz \& Bruno, 2003). Tal categoria é de extrema valia para esse aparato de controle, porque ela vai além daquilo que existe no presente como perigo, privilegiando sua probabilidade de 
manifestação futura. Na forma do risco, o perigo habita sobretudo o futuro; $\mathrm{e}$ a segurança implica previsão e controle das ações presentes tendo em vista conjurar os males por vir - prevenção.

Nota-se que a lógica do risco vai de par com a lógica do banco de dados e com o estatuto da informação nas práticas de controle. Conforme Castel,

um risco não resulta da presença de um perigo preciso, portado por uma pessoa ou um grupo de indivíduos, mas do estabelecimento da relação entre dados gerais impessoais ou fatores (de risco) que tornam mais ou menos provável o advento de comportamentos indesejáveis. ... Assim, prevenir é antes de tudo vigiar, isto é, se colocar em posição de antecipar a emergência de acontecimentos indesejáveis (doenças, anomalias, comportamentos desviantes, atos de delinqüuência etc) no seio de populações estatísticas assinaladas como portadoras de risco' (op. Cit: 145).

Quer se trate da previsão da taxa de mortalidade da população causada pela depressão, ou do aumento da AIDS, os indivídụos são dissolvidos em feixes de informação que irão permitir estimativas. As correlações podem incidir sobre fatores genéticos, hábitos, pertencimento a grupos sociais ou localidades, enfim, sobre a esfera mais superficial e objetiva do sujeito, à qual este passa efetivamente a corresponder. E esta esfera não pressupõe qualquer profundidade psíquica, qualquer fabricação de sentido, já que corpo, sujeito e meio, tornando-se fatores de cálculos, apresentam-se como pura informação visível e manipulável em bancos de dados.

As preocupações com o aumento dos casos de depressạ̃o exemplificam a natureza desse processo e sua conexão com as biotecnologias e tecnologias biomédicas. Em relação a esse transtorno, a Organização Mundial de Saúde prevê uma ampliação expressiva de ocorrências capaz de elevá-lo, em 2020, ao posto de segunda maior causa de mortes. Tais previsões determinam uma demanda por medicamentos antidepressivos mais sofisticados, assim como por marcadores genéticos que permitam avaliar a propensão para o desenvolvimento do transtorno. Confia-se também às pesquisas genômicas a tarefa de criar testes capazes de diagnosticar cada sub-tipo de depressão, facilitando a indicação do medicamento apropriado, de forma a minimizar os efeitos colaterais (Rabinow \& Rose, 2003). Deste modo, as atuais técnicas de governo da população se inclinam para a esfera da gestão da informação e da administração de riscos. $O$ alvo são os indivíduos vinculados sob diversas formas - geneticamente, geograficamente, socialmente, etc...- a fatores que podem desencadear o aparecimento da depressão. Portanto, é nesse âmbito que se coloca o problema do indivíduo como alvo do investimento político 
sobre a vida em seu processo de migração para os bancos de dados: como indivíduo em risco.

No plano das relações e cuidados do indivíduo consigo próprio, também encontramos efeitos destas projeções do corpo informacional e da identidade somática realizadas pelo encontro das biotecnologias com a lógica do banco de dados e do controle dos riscos. Notamos uma curiosa convivência entre a constituição da identidade somática e o aumento da responsabilidade do indivíduo consigo e com o destino de seu corpo e sua vida. Se outrora a previsão de uma predisposição genética era carregada de fatalismo, hoje ela engaja radicalmente a nossa responsabilidade na medida em que esta previsão anuncia também o poder tecnológico de intervenção e a possibilidade de se evitar o que foi previsto. Deste modo, institui-se um regime de cuidados e inquietações relativo às virtualidades do corpo - as enfermidades que se pode vir a ter, o envelhecimento a retardar, a expectativa de vida a aumentar. Essa porção que o sujeito experimenta como sua e ainda não inteiramente presente nele toma-se, assim, um foco privilegiado de atenção ou mesmo de intervenção. (Bruno, 2000).

A informação (sobre riscos de adoecimento e morte, por exemplo) traz consigo a responsabilidade. E esta responsabilidade soa ainda mais estranha na medida em que, como vimos, o perfil ou identidade projetados pelos bancos de dados e técnicas computacionais têm pouquíssimo ou mesmo nenhum vínculo com a experiência. Muitas vezes, o indivíduo é surpreendido pela virtualidade ou risco anunciado. Ressaltamos aqui um estreito vínculo entre informação, poder e dever. Os procedimentos contemporâneos de controle e de incitação ao cuidado consigo visam menos a normalização que a responsabilização. Sua função é informar mais que curar. A gestão de si, do corpo e da saúde implica, portanto, o contato e o acesso à informação e não mais uma relação de interpretação de uma verdade cujo texto se ocultava em substratos profundos da subjetividade. Numa palavra, o par norma-verdade é substituído pelo par informação-responsabilidade. Se os homens modernos reconheciam na norma o princípio que ordenava e exigia uma relação de verdade de si para consigo, a informação sobre os riscos de doença e de morte ordena uma relação de responsabilidade de si para consigo. Passamos, sem nos darmos conta. do poder ao dever: quando a epidemiologia dos fatores de risco anuncia que nossas doenças resultam de um modo de vida que podemos controlar, quando as pesquisas genômicas divulgam uma nova técnica que permite diagnosticar e tratar nossas doenças virtuais ou aquelas de nossos possíveis filhos, nos dotam de um poder que rapidamente se transforma em dever (Bruno, 1997). Ou seja, nos tornamos responsáveis (culpados?) por males que outrora não dependiam de nossas escolhas e ações. Quantas não são as pessoas que sentem uma obrigação quase moral com a ginástica, a dieta etc. Quantas não são as gestantes que se sentem 
moralmente obrigadas a realizar todos os testes e diagnósticos pré-natais, ainda que não tenham clareza sobre que atitude tomar diante das virtualidades antecipadas.

O bio-poder contemporâneo, sustentado pela lógica informacional e preventiva dos bancos de dados, da gestão dos riscos e das biotecnologias, se define como um poder sobre o poder-ser. Podemos destacar ao menos dois níveis de sua atưação: o primeiro é a própria produção de possíveis ou virtualidades a partir da visualização do "possível em sono" que é o nosso genoma e da sua disposição em bancos de dados que, aliados a técnicas computacionais de processamento de informação, projetam perfis de nosso porvir; e o segundo é a intervenção técnica ou controle sobre os possíveis, explicitados no estreito liame ente informação, poder e dever (Bruno, 1997). Diante da informação sobre o que pode vir a ser o seu corpo, sua vida, sua doença, os indivíduos se percebem como podendo e devendo geri-los. Aí reside o embaraço ou o constrangimento da responsabilidade. Não se pode mais agir cegamente, não se pode mais agir impunemente - toda ação tem um preço, pois até mesmo a escolha de não intervir se constitui. como intervenção.

Se os homens modernos podiam experimentar o seu ser como algo que não dependia inteiramente de seu pensamento e de suas ações, hoje tendemos a supor que o que seremos depende ou promete depender de nossas ações. Então somos livres para escolher quem seremos? O bio-poder contemporâneo torna ainda mais obscuros os limites entre a liberdade e a 154 sujeição.

\footnotetext{
Notas

' Sobre o conceito de bio-poder, Cf. Foucault, 1983, 1994a e 1994b.

${ }^{2}$ Em linhas bastante gerais, o Visible Human Project consiste em uma tentativa bem sucedida de digitalizar completamente o corpo humano, na busca de uma visibilidade integral de seus componentes anatômicos. Garcia dos Santos (2004: 268) descreve assim sua origem: ' '... em 1994, foi lançado na rede o primeiro homem a tornar-se Humano Visível. Tratava-se de um prisioneiro texano de 39 anos condenado à morte, cujo corpo foi escolhido para a primeira digitalização integral, por ser são e poder constituir-se como padrão. No final de 1995 foi lançada a Mulher Visível, versão cyber do corpo de uma mulher de 59 anos, desconhecida, doado pelo marido'.

${ }^{3}$ Embora, a Teoria da Comunicação atribuída a Claude Shannon tenha exercido um importante papel nas.formulações da cibernética, a noção de informação empregada por Wiener e seus seguidores é muito mais fisicalista do que comunicacional. Isto significa que, para esses últimos, informação consiste em uma grandeza existente na natureza e, portanto, independente da comunicação e do sentido atribuído pela interação entre agentes humanos. (DUPUY, op. cit.)
} 
${ }^{4}$ Para uma análise pormenorizada da relação constitutiva da dimensão do impensado com o pensamento, ver As Palavras e As Coisas, pp-338-344 (Foucault, 1987).

5 Vale ressaltar que as informações biológicas que irão projetar identidades somáticas não concernem apenas a características ou potencialidades orgânicas, mas também a traços de personalidade e padrões comportamentais.

\section{Referências Bibliográficas}

BRUNO, F. Do sexual ao virtual. São Paulo: Unimarco, 1997.

"Membranes Artificielles: mutations du corps dans la culture technologique contemporaine". Sociétés - Revue de Sciences humaines et sociales, vol. 69, 2000.

CASTEL, R. La gestion des Risques, de l'anti-psychiatrie à l'aprèspsychanalise. Paris: Minuit, 1981.

DELEUZE, G. "Sobre as sociedades de controle". In Conversações. Rio de Janeiro: editora 34, 1992. pp. 219-226.

DUPUY, J.P. Nas origens das ciências cognitivas. São Paulo: editora unesp, 1993.

FOUCAULT, M. Vigiar e Punir. Petrópolis, RJ: Vozes, 1983.

Janeiro: Graal, 1984.

História da Sexualidade I: a vontade de saber. Rio de

As Palavras e as Coisas, RJ: Martins Fontes, 1987.

Gallimard, 1994a.

"Le Sujet et le Pouvoir". In Dits et Écrits IV. Paris:

"La Technologie Politique des Individus". Em Dits et Écrits IV. Paris: Gallimard, 1994b.

GARCIA DOS SANTOS, L. Politizar as novas tecnologias: o impacto sóciotécnico da informação digital e genética. Rio de Janeiro: ed. 34, 2004.

HAYLES, K. How we became post-human: virtual bodies in cibernetics, literature and informatics. Chicago: Chicago Press, 1998

JACOB, F. A lógica da vida- uma história da hereditariedade. Rio de janeiro: Graal, 1983. 
NELKIN, D. e TANCREDI, L. Dangerous Diagnostics: the social power of biological information. Chicago: University of Chicago Press, 1994.

NOVAS, C. ROSE, N. Genetic risk and the birth of the somatic individual. Economy and Society, vol 29 , n 4, november 2000, pp. 485-513.

POSTER, M. The second media age. Cambridge: Polity Press, 1995.

RABINOW, P. "Cortando os laços: fragmentação e dignidade na modernidade tardia". Antropologia da Razão, Rio de Janeiro: Relume dumará, 2002b. , pp.159-84.

RABINOW, P. \& ROSE, N. "Thoughts on the concept of biopower today" http://www.ise.ac.uk/ collections/sociology/ whswho/rose.htm retirado em out, 2003.

ROSE, N. The politics of life itself. Theory, Culture \& Society, vol.18 (6), pp. 1-30, Sage: London, Thousand Oaks and New Delhi, 2002.

SENRA, S. "Tela/Pele” ensaio publicado na Folha de São Paulo, suplemento Mais!, 30/04/2000

VARELA, F.; THOMPSON, E.; ROSCH, E. L'inscription corporelle de l'esprit. Paris: Seuil, 1993

VAZ, P. \& BRUNO, F.. "Types of self-surveillance: from abnormality to individuals 'at risk'"' in Surveillance \& Society 1 (3): Foucault and Panopticism revisited, 2003.

VIEIRA, J. V. "Anatomias do visível: cinema, corpo e máquina da ficção científica" in NOVAES, A. (org.) O Homem-Máquina- a ciência manipula o corpo, Rio de Janeiro: companhia das Letras, 2003. 